\title{
UPAYA YANG DAPAT DI LAKUKAN PERAWAT UNTUK MENCEGAH RESIKO HAZARD KIMIA DAN HAZARD FISIK RADIASI
}

Nabila Rahmadhani

@rahmadhaninabila2@gmail.com

\begin{abstract}
The implementation of occupational safety and health (K3) is one form of effort to create a work place that is safe, healthy, free from environmental pollution, so as to reduce occupational accidents and occupational diseases. Every workplace always has a risk of accidents. The size of the risk that occurs depends on the type of industry, technology and the risk control efforts undertaken. In the workplace there are sources of hazards that range from low hazard capacities to high hazards. Types of hazard categories are physical hazards, chemical hazards, mechanical hazards, electrical hazards, ergonomic hazards, habit hazards, radiation physical hazards, environmental hazards, biological hazards, and psychological hazards.
\end{abstract}

Keywords: chemical hazard, radiation physical hazard

\begin{abstract}
Abstrak
Pelaksanaan keselamatan dan kesehatan Kerja (K3) adalah salah satu bentuk upaya untuk menciptakan tempat kerja yang aman, sehat, bebas dari pencemaran lingkungan, sehingga dapat mengurangi kecelakaan kerja dan penyakit akibat kerja. Setiap tempat kerja selalu mempunyai risiko terjadinya kecelakaan. Besar kecilnya risiko yang terjadi tergantung dari jenis industri, teknologi serta upaya pengendalian risiko yang dilakukan. Di tempat kerja terdapat sumber bahaya yang beraneka ragam mulai dari kapsitas bahaya yang rendah hingga bahaya yang tinggi. Jenis kategori hazard adalah bahaya fisik, bahaya kimia, bahaya mekanik, bahaya elektrik, bahaya ergonomi, bahaya kebiasaan, bahaya fisik radiasi, bahaya lingkungan, bahaya biologi, dan bahaya psikologi.
\end{abstract}

Kata kunci: hazard kimia, hazard fisik radiasi 


\section{Latar belakang}

Menurut International Labour Organization (ILO) kesehatan keselamatan kerja atau Occupational Safety and Health adalah meningkatan dan memelihara derajat tertinggi semua pekerja baik secara fisik, mental, dan kesejahteraan sosial di semua jenis pekerjaan, mencegah terjadinya gangguan kesehatan yang diakibatkan oleh pekerjaan, melindungi pekerja pada setiap pekerjaan dari risiko yang timbul dari faktor-faktor yang dapat mengganggu kesehatan, menempatkan dan memelihara pekerja di lingkungan kerja yang sesuai dengan kondisi fisologis dan psikologis pekerja dan untuk menciptakan kesesuaian antara pekerjaan dengan pekerja dan setiap orang dengan tugasnya.

Pelaksanaan keselamatan dan kesehatan Kerja (K3) adalah salah satu bentuk upaya untuk menciptakan tempat kerja yang aman, sehat, bebas dari pencemaran lingkungan, sehingga dapat mengurangi kecelakaan kerja dan penyakit akibat kerja. Dalam, pasal 23, penjelasan undang-undang nomor 23 tahun 1992 tentang kesehatan menjelaskan bahwa upaya kesehatan harus diselenggarakan di semua tempat kerja, khususnya tempat kerja yang mempunyai risiko bahaya kesehatan, mudah terjangkit penyakit atau mempunyai karyawan paling sedikit 10 orang (Depkes. 2009).

Setiap tempat kerja selalu mempunyai risiko terjadinya kecelakaan. Besar kecilnya risiko yang terjadi tergantung dari jenis industri, teknologi serta upaya pengendalian risiko yang dilakukan.
Kecelakaan akibat kerja adalah kecelakaan berhubung kerja pada perusahaan. Hubungan kerja ini dapat diartikan kecelakaan terjadi dikarenakan pekerjaan atau pada waktu melaksanakan pekerjaan. Secara umum kecelakaan disebabkan oleh tindakan perbuatan manusia yang tidak memenuhi keselamatan ( unsafe human action) dan keadaan lingkungan yang tidak aman (unsafe condition) (Suma'mur, 2014).

Harrianto (2009) menjelaskan bahwa bahaya kerja adalah setiap keadaan dalam lingkungan kerja yang berpotensi untuk terjadinya penyakit atau gangguan akibat kerja. Bahaya kerja terdiri dari bahaya kimiawi, bahaya fisik, bahaya biologis, bahaya ergonomis, dan bahaya psikologi. Dari ke lima kategori bahaya tersebut serta menilik peran dan tanggung jawab perawat pada pada penjelasan sebelumnya, sudah jelas seorang perawat beresiko mengalami atau terpajan kelima bahaya tersebut, apalagi jika melakukan aktifitas kerja di unit yang memang berurusan dengan bahaya-bahaya di atas.

Kecelakaan kerja yang tinggi di setiap bidang pekerjaan disebabkan oleh multifaktor. Salah satu penyebab kecelakaan kerja yaitu tidak diterapkannya analisa potensi bahaya dan penilaian risiko terhadap bahaya-bahaya yang ada sehingga tidak terdapat pencegahan yang memadai terhadap bahaya yang kemungkinan dapat terjadi di perusahaan (Dualembang, 2017). Sebagai upaya pengendalian risiko kecelakaan dan penyakit akibat kerja, perlu dilakukan identifikasi sumber bahaya yang ada di tempat kerja dan dievaluasi tingkat risikonya 
serta dilakukan pengendalian yang memadai. Pengendalian risiko dilakukan pada seluruh bahaya yang ditemukan dalam proses identifikasi bahaya dan mempertimbangkan peringkat risiko untuk menentukan prioritas dan cara pengendaliannya, dalam menentukan pengendalian harus memperhatikan hierarki pengendalian mulai dari eliminasi, substitusi, pengendalian teknis, administratif dan penyediaan alat keselamatan yang disesuaikan kondisi organisasi dan jenis bahaya (Dankis, 2015).

\section{Metode}

Dalam melakukan kanjin ini metode penulisan yang di gunakan penulis adalah metode literature review, yaitu metode uraian tentang teori, temuan dan bahan penelitian lain yang diperoleh dari bahan acuan untuk dijadikan landasan kegiatan penelitian untuk menyusun kerangka pemikiran yang jelas dari perumusan masalah yang ingin diteliti. Sumber yang menjadi literatur dalam pembuatan kajian ini adalah buku bacaan, jurnal, tesis juga maupun ebook yang berhubunga dengan upaya mencegah resiko hazard kimia dan hazard upaya mencegah resiko fisik radiasi yaitu bagaimana tanggungjawab perawat dalam menekan adanya resiko dari hazard fisik radiasi dan hazard kimia di lingkungan tempat kerja. Sehingga keselamatan perawat dalam melakukan tugas dapat lebih aman untuk diri perawat dan untuk pasien yang akan di beri perawatan.

Kajian ini juga merupakan kajian yang dilakukan secara bebas dimana dalam melakukan kajian ini penulis dengan membandingkan dari berbagai sumber dengan artikel satu dan artikel-artikel yang berhubungan dengan kajian yang di lakukan dan hasil dari perbandingan tersebut di tulis secara berurutan dan bertauran dalam hasil kajian ini agar dapat di pahami dengan baik dan menghasilkan kajian yang dapat di terima dengan baik. Sehingga penulisan kajian ini dapat bermanfaat untuk banyak kalangan

Hasil

Hasil dari metode ini adalah Keselamatan dan Kesehatan Kerja (K3) adalah salah satu bentuk upaya untuk menciptakan tempat kerja yang aman, sehat, bebas dari pencemaran lingkungan, sehingga dapat mengurangi dan bebas dari kecelakaan kerja danp enyakit akibat kerja yang pada akhirnya dapat meningkatkan efisiensi dan produktivitas kerja. Namun dalam penerapan Keselamatan dan Kesehatan Kerja (K3) masih juga banyak didapati perawat perawat yang terkena penyakit akibat kerja yang di lakukan di klinik, rumah sakit atau instansi kesehatan lainnya.

Dalam melakukan tugasnya perawat sangat berseiko dengan kejadian kecelakaan kerja jika perawat tidak disiplin dalam melakukan pekerjaanya dan berhubungan dengan pengetahuan perawat mengenai resiko perawat terkena berbagai bahaya mulai dari bahaya fisik, bahaya kimia, bahaya mekanik, bahaya elektrik, bahaya ergonomi, bahaya kebiasaan,bahaya fisik radiasi, bahaya lingkungan, bahaya biologi, dan bahaya psikologi. Sebagai upaya pengendalian risiko kecelakaan dan penyakit akibat kerja, perlu dilakukan identifikasi sumber bahaya yang ada di tempat kerja dan 
dievaluasi tingkat risikonya serta dilakukan pengendalian yang memadai.

. Pengendalian risiko dilakukan pada seluruh bahaya yang ditemukan dalam proses identifikasi bahaya dan mempertimbangkan peringkat risiko untuk menentukan prioritas dan cara pengendaliannya, dalam menentukan pengendalian harus memperhatikan hierarki pengendalian mulai dari eliminasi, substitusi, pengendalian teknis, administratif dan penyediaan alat keselamatan yang disesuaikan kondisi organisasi dan jenis bahaya.

Berbagai upaya dapat di lakukan perawat dalam mencegah terjadinya hazard fisik radiasi juga hazard kimia mulai dari memasang SOP pengelasan di tempat kerja, menyediakan kacamata berlensa (untuk melindungi dari bahaya radiasi sinar), peningkatan pengetahuan terkait dengan cara bekerja yang aman dan mengantisipasi bahaya yang muncul dari pengelasan serta pengawasan penggunaan APD di tempat kerja.

\section{Pembahasan}

Menurut Department of Occupational Safety and Health Ministry Of Human Resources Malaysia (2008) bahwa pengendalian terhadap bahaya dilingkungan kerja adalah tindakan-tindakan yang diambil untuk meminimalisir atau mengeliminasi risiko kecelakaan kerja dengan tahap- tahap yang ada seperti Eliminasi, Subtitusi, Engineering control, Administratif control dan Alat Pelindung Diri (APD). Tindakan pengendalian risiko ini digunakan untuk bahaya dengan risiko tinggi. Berdasarkan hasil penilaian risiko ada 2 bahaya yang masuk dalam kategori risiko tinggi yaitu ancaman dari hewan berupa cakaran, gigitan bahkan tendangan dari pasien dan permukaan lantai licin tetapi pengaturan desain untuk penyimpanan kandang juga merupakan kebutuhan rumah sakit, hal ini disebabkan dari beberapa petugas mengeluh tentang ruang yang sempit dengan penggabungan beberapa kandang

Di tempat kerja terdapat sumber bahaya yang beraneka ragam mulai dari kapsitas bahaya yang rendah hingga bahaya yang tinggi. Jenis kategori hazard adalah bahaya fisik, bahaya kimia, bahaya mekanik, bahaya elektrik, bahaya ergonomi, bahaya kebiasaan, bahaya lingkungan, bahaya biologi, dan bahaya psikologi (Wijaya, et, al, 2015). Hadi et, al (2014) membedakan jenis hazard terbagi atas . bahaya fisik, bahaya ergonomi, bahaya kimia, bahaya biologi, dan bahaya psikologi. Bahaya hazard dapat dibagi menjadi 3 kategori, yaitu bahaya kesehatan, bahaya kecelakaan, dan bahaya lingkungan (Halim \& Panjaitan, 2016)

Bahan kimia berbahaya adalah bahan kimia yang memiliki sifat reaktif dan atau sensitif terhadap perubahan/kondisi lingkungan yang dengan sifatnya tersebut dapat menimbulkan bahaya bagi lingkungannya. Bahan kimia beracun adalah bahan kimia yang dalam jumlah kecil menyebabkan bahaya terhadap kesehatan manusia apabila terserap dalam tubuh melalui pernafasan, tertelan, atau kontak melalui kulit.

Identifikasi bahaya adalah suatu proses yang dikendalikan oleh manajemen 
dengan menilai hasil dari proses identifikasi dan menentukan apakah tindakan dilakukan dengan segera dengan bahaya yang terjadi. Potensi bahaya kimia merupakan paparan yang terjadi pada pekerja dengan berbagai macam bahan yang mengandung racun dengan paparan terjadi dalam kondisi kerja normal yang berdampak pada efek yang merugikan. Penilaian risiko adalah analisis sistematis untuk mengidentifikasi atau mengukur frekuensi atau probabilitas dan besarnya kerugian kepada penerima karena paparan bahaya (fisik, kimia, biologi, ergonomi dan psikososial) kegagalan yang melibatkan peristiwa terhadap manusia

Bahaya Kimia, Yaitu terkena cairan bahan kimia yang mengalami iritasi ringan sampai tinggi jika terkena anggota tubuh. dan pada area chemical boiler menggunakan beberapa bahan kimia untuk proses pada area ini. Untuk bahaya kimia yaitu terkena cairan kimia atau tekanan gas berlebih akan mengakibatkan iritasi mata dan kulit jika terkena anggota tubuh dan terserap ke dalam mata dan kulit serta gangguan pernafasan karena menghirup gas/uap

pengendalian/pengurangan risiko dapat dilakukan dengan menggunakan APD (googles, masker) Material Safety Data Sheet (MSDS), rambu K3 dan pembatasan akses pada area tersebut agar tidak sembarang orang memasuki area tersebut. Serta karyawan harus melakukan pengujian kesehatan setiap tahun sesuai ketentuan perusahaan. Baik yang terkena bahan kimia maupun yang tidak terkena bahan kimia tersebut. Pihak yang berwenang harus selalu melakukan monitoring lingkungan kerja tersebut, serta larangan makan dan minum di tempat kerja. Hal ini sesuai dengan UU No. 1 Tahun 1970 tentang keselamatan kerja pada pasal 13, yaitu kewajiban bila memasuki tempat kerja dan Kepmenaker. 333/MEN/1989 tentang diagnosis dan pelaporan penyakit akibat kerja dan Kepmenaker. 187/MEN/1999 tentang pengendalian bahan kimia berbahaya di tempat kerja. Serta PP No.74/2001 tentang pengelolaan bahan berbahaya dan beracun. serta di lakukan sosialisai penanganan bahan kimia dan pelatihan pengunaan APD yang benar.

Radiasi atau pancaran dapat didefinisikan sebagai suatu proses dimana energidilepaskan oleh suatu atom. Menurut Badan Tenaga Nuklir Nasional, radiasi adalah energi yang dipancarkan dalam bentuk partikel atau gelombang. Jadi radiasi kedokteran adalah energi yang dipancarkan oleh atom dalam bentuk partikel atau gelombang yangdigunakan dalam dunia kedokteran, baik untuk tujuan diagnosis maupun tujuanpengobatan (terapi). Ada beberapa radiasi yang kita terima setiap saat, baik yang berasaldari alam maupun dari buatan manusia. Radiasi tersebut ada yang bermanfaat atauberdampak positif dan ada yang merugikan atau berdampak negatif bagi tubuh manusia,hewan, maupun tumbuh-tumbuhan

Risiko dari bahaya radiasi berada pada tingkat risiko yang tinggi. Sehingga diperlukan pengendalian untuk menghilangkan atau mengurangi risiko tersebut. Rekomendasi pengendalian yang 
diberikan adalah memasang SOP pengelasan di tempat kerja, menyediakan kacamata berlensa (untuk melindungi dari bahaya radiasi sinar), peningkatan pengetahuan terkait dengan cara bekerja yang aman dan mengantisipasi bahaya yang muncul dari pengelasan serta pengawasan penggunaan APD di tempat kerja.

Kepala Rumah Sakit yang bertugas sebagai penanggung jawab keselamatan radiasi di instalasi radiologi RSK Paru serta Kepala Instalasi Radiologi dimana memiliki tanggung jawab :

1. menyediakan, melaksanakan, mendokumentasikan program proteksi keselamatan radiasi

2. memverifikasi secara sistematis bahwa hanya personil yang sesuai dengan kompetensi yang bekerja dalam penggunaan pesawat sinar- $\mathrm{X}$

3. menyelenggarakan pelatihan Proteksi Radiasi d. menyelenggarakan pemantauan kesehatan bagi Pekerja Radiasi

4. menyediakan perlengkapan Proteksi Radiasi.

5. melaporkan kepada Kepala BAPETEN mengenai pelaksanaan program proteksi dan keselamatan radiasi, dan verifikasi keselamatan.

Kewajiban dan tanggung jawab

Petugas Proteksi Radiasi antara lain :

1. Memberi instruksi kepada pekerja radiasi

2. Mengambil tindakan untuk menjamin tingkat penyinaran serendah mungkin dan tidak akan pernah mencapai batas tertinggi yang berlaku serta pelaksanaan pengelolaan limbah radioaktif sesuai ketentuan

3. Mencegah perubahan yang dapat menimbulkan kecelakaan

4. Mencegah orang yang tidak berkepentingan masuk ke daerah radiasi

5. menyarankan pemeriksaan kesehatan

6. Memberi penjelasan dan menyediakan perlengkapan proteksi radiasi kepada pengunjung atau tamu bila diperlukan kewajiban dan tanggung jawab pekerja radiasi yaitu :

1. Mengetahui, memahami, melaksanakan ketentuan keselamatan radiasi

2. Memanfaatkan peralatan keselamatan radiasi yang tersedia, bertindak hati- hati dan bekerja secara aman untuk melindungi dirinya maupun pekerja lain

3. Melaporkan setiap kejadian kecelakaan bagaimanapun kecilnya kepada PPR

4. Melapor gangguan kesehatan yang dirasakan, yang diduga akibat penyinaran lebih atau masuknya zat radioaktif ke dalam tubuhnya.

Pengendalian risiko secara hirarki dilakukan dengan pendekatan sebagai berikut :

1. Hindari risiko dengan mengambil keputusan untuk menghentikan kegiatan atau penggunaan proses, bahan, alat yang berbahaya. 
2. Mengurangi kemungkinan terjadi (Reduce Likehood)

3. Mengurangi konsekuensi kejadian (Risk Transfer)

4. Menanggung risiko yang tersisa. Penanganan risiko tidak mungkin menjamin risiko atau bahaya hilang semuanya, sehingga masih ada sisa risiko (Residual Risk) yang harus ditanggung perusahaan

\section{Kesimpulan}

Prinsip utama dalam menangani bahanbahan berbahaya tersebut adalah mendapat informasi sebanyak mungkin lebih dahulu sebelum menanganinya. Setiap tempat kerja selalu mempunyai risiko terjadinya kecelakaan. Besar kecilnya risiko yang terjadi tergantung dari jenis industri, teknologi serta upaya pengendalian risiko yang dilakukan. Identifikasi bahaya adalah suatu proses yang dikendalikan oleh manajemen dengan menilai hasil dari proses identifikasi dan menentukan apakah tindakan dilakukan dengan segera dengan bahaya yang terjadi. Potensi bahaya kimia merupakan paparan yang terjadi pada pekerja dengan berbagai macam bahan yang mengandung racun dengan paparan terjadi dalam kondisi kerja normal yang berdampak pada efek yang merugikan. Risiko dari bahaya radiasi berada pada tingkat risiko yang tinggi. Sehingga diperlukan pengendalian untuk menghilangkan atau mengurangi risiko tersebut.

\section{Daftar pustaka}

Dankis, NDV. 2015. Risk Assessment Perusahaan Export Sepatu pada
Bagian Line Upper PT. X. The Indonesian Journal of Occupational Safety and Health, 4 (1). 22-32

Dualembang, S. 2017. Analisis Penilaian Risiko Terhadap Potensi Bahaya Pekerjaan dengan Metode Job Safety Analysis pada Pekerja Bagian Proses Produksi PT. Kerismas Witikco Makmur Bitung. Media Kesehatan 9 (3). 1-10.

Hadi, M.H., et al. 2016. Application of HIRARC in Palm Oil Mill Industry. Occupational Safety and Helath in Comodity Agriculture. Malaysia: Universiti Putra Malaysia

Harjanto. Nur Tri. Suliyanto, Endang Sukesi I. (2011). Manajemen Bahan Kimia Berbahaya Dan Beracun Sebagai Upaya Keselamatan Dan Kesehatan Kerja Serta Perlindungan Lingkungan. 4(8). 54-67.

Irzal. 2016. Dasar-Dasar Kesehatan dan Keselamatan Kerja. Jakarta: Kencana.

Pertiwi. Yudha Nurhantari. Santosa Budihardjo. (2019). Hazard identification, risk assesment and risk control serta penerapan risk mapping pada Rumah Sakit Hewan Prof. Soeparwi Universitas Gadjah Mada.(BKM Journal of Community Medicine and Public Health, 35(2).55-64.

Ratulangi, A, \& Josephus, J,B,S.(2013). Hubungan Pengetahuan, Sikap dengan Tindakan terhadap K3RS pada Perawat di Siloam Hospital Manado. Junal FKM Unsrat. 
Simamora, R. H. (2019). Pengaruh Penyuluhan Identifikasi Pasien dengan Menggunakan Media Audiovisual terhadap Pengetahuan Pasien Rawat Inap. Jurnal Keperawatan Silampari, 3(1), 342351.

Simamora, R. H. (2020). Learning of Patient Identification in Patient Safety Programs Through Clinical Preceptor Models. Medico Legal Update, 20(3), 553-556.

Simanjuntak. Julianna . Anita Camelia. Imelda G. Purba. (2013). Penerapan Keselamatan Radiasi Pada Instalasi Radiologi di Rumah Sakit Khusus (RSK) Paru Provinsi Sumatera Selatan Tahun 2013. Jurnal Ilmu Kesehatan Masyarakat, 4(3). 245253

Suma'mur, PK. 2014. Keselamatan Kerja dan Pencegahan Kecelakaan Cetakan 8. Jakarta: PT. Toko Gunung Agung.

Supriyadi. Fauzi Ramdan. (2017). Identifikasi Bahaya dan Penilaian Resiko Pada Divisi Boiler Menggunakan Metode Hazard Identification Risk Assessment and Risk Contril (HIRARC). Journal of Industrial Hygiene and Occupational Health, 1(2). 161-177.

Wijaya, A., et al. 2015. Evaluasi Kesehatan dan Keselamatan Kerja dengan Metode HIRARC pada PT. Charoen Pokphand Indonesia, Jurnal Titra, 3(1). 29-34. 